American Journal of Applied Sciences 6 (10): 1781-1787, 2009

ISSN 1546-9239

(C) 2009 Science Publications

\title{
Development and Validation of High Performance Liquid Chromatographic Method for the Simultaneous Determination of Ceftazidime and Sulbactam in Spiked Plasma and Combined Dosage form-Zydotam
}

\author{
Masoom Raza Siddiqui, Abu Tariq, Manu Chaudhary, K. Dinesh Reddy, Prithvi Singh Negi, \\ Jitendra Yadav, Nitya Srivastava, Sanjay Mohan Shrivastava and Rajkumar Singh \\ Venus Medicine Research Centre, Hill Top Industrial Estate, EPIP Phase I, \\ Jharmajri (Extn.) Bhatoli Kalan, Baddi, Solan (HP), India-173205
}

\begin{abstract}
Problem statement: To develop a sensitive method to determine simultaneously ceftizidime and sulbactam in spiked plasma and combined formulation. Approach: In this study an isocratic High performance liquid chromatographic method with UV detection at $230 \mathrm{~nm}$ was described for simultaneous determination of Ceftazidime and sulbactam sodium in plasma and combined dosage form. Chromatographic separation of two drugs was achieved on a Hypersil ODS C18 column using a mobile phase consisting of a binary mixture of acetonitrile and tetrabutyl ammonium hydroxide adjusted to $\mathrm{pH} 5.0$ with orthophosphoric acid in ratio 25:75. Results: The developed performance liquid chromatographic method offers symmetric peak shape, good resolution and reasonable retention time for both drugs. Linearity, accuracy and precision were found to be acceptable over the concentration range of $125-625 \mathrm{ppm}$ for Ceftazidime and 62.5-312.5 ppm for sulbactam sodium. Conclusion: The results showed that this method could be well used for the simultaneous estimation of Ceftazidime and Sulbactam in plasma and combined formulation.
\end{abstract}

Key words: Liquid chromatography, ceftazidime pentahydrate, sulbactam sodium, tetrabutyl ammonium hydroxide

\section{INTRODUCTION}

Ceftazidime,[(6R,7R)-7-[(Z)-2-(2-aminothiazol-4yl)-2-(2-carboxyprop-2-oxyimino)acetamidol]-3(pyridinum-1-ylmethyl)ceph-3-em-4-carboxylate] is a third generation cephalosporin antibiotics characterized by a broad antimicrobial spectrum and resistant to $\beta$ lactamase producing organism in addition to its enhanced in vitro activity against a wide veriaty of gram negative organisms, particularly pseudomanas aeruginosa and Pseudomonas cepacia ${ }^{[1,2]}$.

Sulbactam, Sodium (2S,5R)-3,3-dimethyl-7-oxo-4thia-1-azabicyclo[3.2.0]heptane-2-carboxylate 4,4dioxide, like other $\beta$ lactamase inhibitors, can be combined with one of many $\beta$ lactam antibiotics to prevent their destruction by $\beta$ lactamase for the treatment of infection due to variety of organism staphylococuus aureus, Haemophilius influenza ${ }^{[3]}$. Both ceftazidime $^{[4]}$ and sulbactam ${ }^{[4]}$ are listed individually in USP.

A literature survey revealed that several methods have been used for estimation of ceftazidime alone which includes Spectrophotometry ${ }^{[5-9]}$, High
Performance Liquid Chromatography (HPLC) ${ }^{[10-12]}$ and in combination with pyridine ${ }^{[13]}$ Vancomycin $^{[14]}$ and cefepime $^{[15]}$ by HPLC. Sulbactam was assayed successfully by Spectrophotometry ${ }^{[16]}$ Capillary Isotachophoresis $^{[17]}$ HPLC ${ }^{[18-21]}$ and Gas Chromatography-Mass Spectrometry (GC-MS) ${ }^{[22]}$. Sulbactam along with clavulonic Acid $^{[23-24]}$, Tazobactam $^{[25]}$, Rifampicin ${ }^{[26]}$ was determined by HPLC. Sulbactam in combination with ampicillin sodium, amoxicillin and piperacillin sodium were determined by UV spectrophotometry and HPLC respectively ${ }^{[27-30]}$.

Zydotam (Ceftazidime-Sulbactam) is a sterile combination of Sulbactam sodium and ceftazidime pentahydrate available as dry powder for injection. Zydotam is supplied in strengths equivalent to $750 \mathrm{mg}$, 1.5 and $3.0 \mathrm{~g}$ with Solvent for injection. It is administered as intramuscular and intravenous injection after reconstitution with solvent supplied with the pack. The product Zydotam is manufactured by Venus Remedies Limited, India. Zydotam is a synergistic antimicrobial combination with marked in vitro antibacterial activity against a broad spectrum of

Corresponding Author: Rajkumar Singh, Venus Medicine Research Centre, Hill Top Industrial Estate, EPIP Phase I, Jharmajri (Extn.) Bhatoli Kalan, Baddi, Solan (HP) India-173205 Tel: +91-1795-302018/302133 
organisms. Sulbactam not only potentates the antibacterial activity of Ceftazidime but also exhibits a moderate antibacterial activity. By forming a protein complex with beta-lactamases, Sulbactam irreversibly blocks their destructive hydrolytic activity. Thus, Sulbactam addition extends the spectrum of activity of Ceftazidime. As Sulbactam also binds with some penicillin binding proteins, sensitive strains are often rendered more susceptible to the Zydotam than Ceftazidime alone. In bacterial strains that produce either low amounts of beta-lactamase, or none at all, a synergistic effect is observed when sulbactam is associated with Ceftazidime that has a complementary affinity for the target sites. Zydotam is active against all the organisms sensitive resistant to Ceftazidime. The combination of Ceftazidime and Sulbactam is used to improve cost effectiveness of antimicrobial therapy as it replaces regimens that use multiple drug leading to high incidence of adverse reaction.

Although both the drugs are available in market in combined dosage from yet it lacks a validated method for its estimation in combined formulation. Thus for the quality control and research laboratory purpose it was the need to develop and validate an analytical method for the simultaneous determination of both Ceftazidime and Sulbactam in combined formulation.

The present communication describes isocratic high performance liquid chromatographic method for simultaneous determination of Ceftazidime pentahydrate and Sulbactam sodium, which would be a better alternate for the quality control of the developed formulation. As to the best of our knowledge there is no method present for the simultaneous determination of ceftazidime and Sulbactam in combined dosage form. This study achieved satisfactory results in terms of selectivity, linearity, precision and accuracy under simple chromatographic condition. Adding to its advantage, the method is time saving and requires no pretreatment.

\section{MATERIALS AND METHODS}

Reagents and standard: Ceftazidime pentahydrate and sulbactam sodium Reference Standards (RS) of United States Pharmacopoeia (USP) were bought from Sigma, United States. Zydotam, a Fixed Dose Combination (FDC) was obtained from manufacturer, Venus Remedies Limited, India. Each vial contains $1 \mathrm{~g}$ Ceftazidime and $0.5 \mathrm{~g}$ sulbactam. Tetrabutyl Ammonium Hydroxide (TBAH), acetonitrile and phosphoric acid was of chromatographic grade and was obtained from Merck, Mumbai India. All other chemicals were of analytical reagent grade unless specified.
Apparatus: Agilent 1200 series liquid chromatographic system equipped with G1311A quaternary pump was used for the chromatographic separation. Agilent variable UV/vis detector and a G1329A Auto Injector. EZ Chrome Elite software was employed for data collecting and processing.

Chromatographic conditions: Chromatographic Separation was performed on ODS Hypersil C-18 Stainless Steel column with dimension $250 \times 4.6 \mathrm{~mm}$, $5 \mu$ (Thermo Electron Corporation). The mobile phase consisting of a binary mixture of Acetonitrile and TBAH adjusted to $\mathrm{pH} 5.0$ with orthophosphoric acid in ratio 25: 75, was delivered at rate of $1.6 \mathrm{~mL} \mathrm{~min}^{-1}$. The mobile phase was filtered through $0.45 \mu \mathrm{m}$ membrane filter (Millipore) and degassed prior to use. Separation was performed at ambient temperature i.e., $25^{\circ} \mathrm{C}$ and detection was made at $230 \mathrm{~nm}$. The injection volume was $20 \mu \mathrm{L}$ with a run time of $12 \mathrm{~min}$.

Preparation of standard sample dissolve an accurately weighed quantity of Ceftazidime (RS) $50 \mathrm{mg}$ and sulbactam sodium (RS) $25 \mathrm{mg}$ in mobile phase and dilute quantitatively and stepwise, if necessary, with mobile phase to obtain a solution having a known concentration of about $500 \mathrm{ppm}$ of Ceftazidime and 250 ppm sulbactam sodium.

Preparation of sample solution: Transfer about $75 \mathrm{mg}$ of Zydotam, (Ceftazidime pentahydrate and sulbactam sodium for injection), accurately weighed, to $100 \mathrm{~mL}$ volumetric flask. Add mobile phase, swirl to dissolve, dilute with mobile phase to volume and mix.

Data analysis: For determination of Ceftazidime and sulbactam separately inject equal volumes of the standard preparation and the assay preparation into the chromatograph, record the chromatograms and measure the responses for the major peaks.

\section{DISCUSSION}

Method Development and validation: A variety of mobile phase were investigated in the development of the HPLC method suitable for the analysis of Ceftazidime and Sulbactam in bulk and commercial dosage form. This include methanol-phosphate buffer ( $\mathrm{pH}$ 3-7), Acetonitrile-phosphate buffer ( $\mathrm{pH}$ 3-7) TBAH-Acetonitrile ( $\mathrm{pH}$ 3-7). Taking in consideration the instability of ceftazidime and sulbactam sodium in strong alkaline and strong acidic condition, the $\mathrm{pH}$ value of the mobile phase should was limited within the range of 3-7. Since mild acidic $\mathrm{pH}$ favours the retention and separation of two drugs on C-18 column. After 
some trials TBAH with $\mathrm{pH} 5.0$ was finally selected. Acetonitrile is the most commonly used solvent for LC analysis and often is the first choice for many researchers. Therefore, a binary mixture of acetonitrile and TBAH buffer became the mobile phase for the determination of the two drugs. Firstly, various concentrations of TBAH buffer were tried to find the proper one to achieve our purpose. As a result, $0.1 \mathrm{~N}$ TBAH buffer was found to be ideal for our analysis. Then, the proportion of acetonitrile and TBAH buffer in mobile phase was determined by varying the proportion of acetonitrile and TBAH buffer from 10:90, 20:80, 30:70-25:75. Finally, the 25:75 ratio of acetonitrile and $0.1 \mathrm{~N}$ TBAH buffer was used for the simultaneous determination of the two drugs, this system produced symmetric peak shape, good resolution and reasonable retention time, high theoretical plate value and asymmetry less than 2.0 in the case of both drugs. The retention times of Ceftazidime pentahydrate and sulbactam sodium for six repetition were $4.11 \pm 0.007$ and $6.21 \pm 0.015 \mathrm{~min}$ respectively. A typical chromatogram of a sample solution is shown in Fig. 1.

Specificity: Specificity is the ability of the method to accurately measure the analyte in the presence of all potential sample components. The response of analyte in test mixtures containing analyte and all potential sample components in compound with response of a solution containing only analyte. The analyte peak is evaluated for peak purity from the nearest eluting peak. For this purpose a solution containing $500 \mathrm{ppm}$ of Ceftazidime and sulbactam sodium was injected and peak purity was done. The acceptance criteria for peak purity is that the purity angle should be less than purity threshold. Result of peak purity analysis was found to be satisfactory, purity angle and purity threshold for Ceftazidime and sulbactam is 1.00 and 0.99 , respectively.

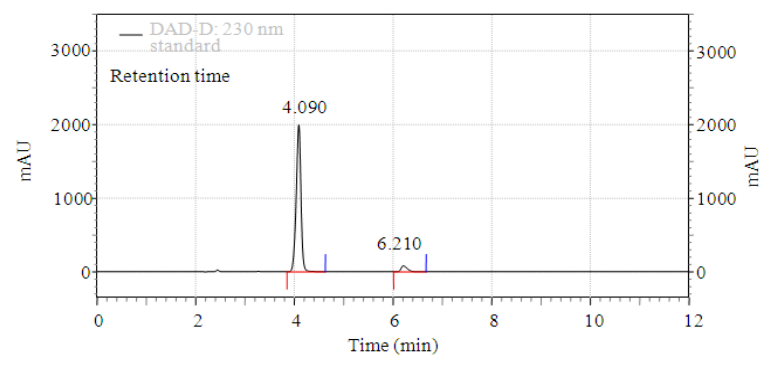

Fig. 1: A typical LC chromatogram of a mixture of Ceftazidime pentahydrate 500 ppm (Peak No. 1) and sulbactam sodium, $250 \mathrm{ppm}$ (peak No. 2) achieved using the proposed method

\section{RESULTS}

Forced Degradation Study: This was demonstrated by carried out by treating the mixture of ceftazidime and Sulbactam with $0.5 \mathrm{~N} \mathrm{HCl}, 0.5 \mathrm{~N} \mathrm{NaOH}, 3 \% \mathrm{H}_{2} \mathrm{O}_{2}$, heating in water bath at $80^{\circ} \mathrm{C}$ for 4 hour and keeping under UV light for $12 \mathrm{~h}$. The samples were degraded to levels where the contents of ceftazidime and sulbactam in the samples were lowered to that of the original level.

Acid degradation: Accurately weighed quanlity of Ceftazidime and Sulbactam equivalent to $50 \mathrm{mg}$ of ceftazidime and $25 \mathrm{mg}$ of sulbactam was transferred to $100 \mathrm{~mL}$ beaker. Then $10 \mathrm{~mL} 0.5 \mathrm{~N} \mathrm{HCl}$ was added to it and heated in the water bath at $60^{\circ} \mathrm{C}$ for $4 \mathrm{~h}$. Cooled and neutralized with $0.5 \mathrm{~N} \mathrm{NaOH}$, sample was diluted up to $100 \mathrm{~mL}$ with mobile phase. This solution was injected into the HPLC System. The chromatogram is shown in Fig. 2.

Thermal degradation: Accurately weighed quantity of Ceftazidime and Sulbactam equivalent to $50 \mathrm{mg}$ of ceftazidime and $25 \mathrm{mg}$ of sulbactam was transferred to $100 \mathrm{~mL}$ beaker and was kept as such in oven at $100^{\circ} \mathrm{C}$ for $4 \mathrm{~h}$. Cooled and sample was dissolved in $100 \mathrm{~mL}$ mobile phase. This solution was injected into the HPLC system. The chromatogram is shown in Fig. 3.

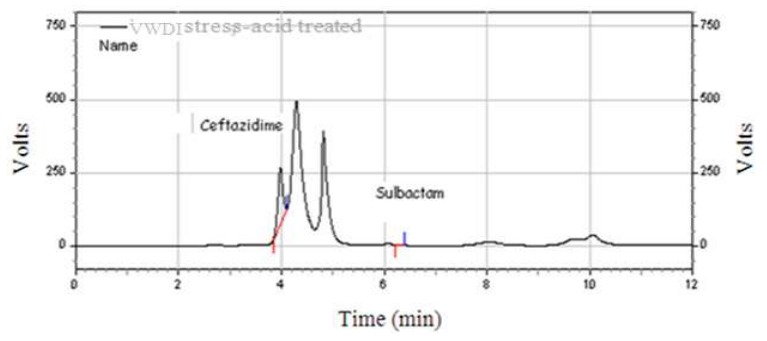

Fig. 2: Chromatogram of Ceftazidime pentahydrate and sulbactam sodium after subjected to acid degradation

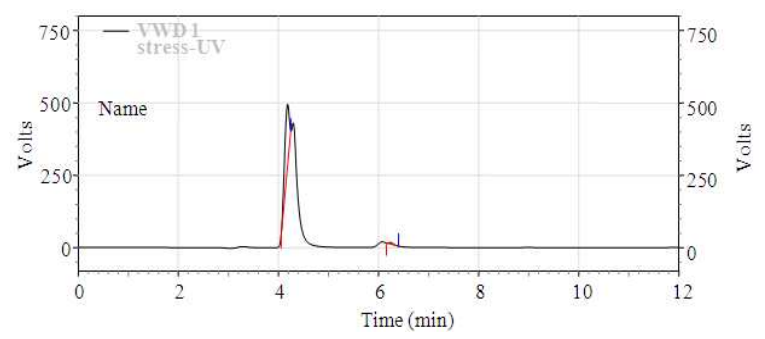

Fig. 3: Chromatogram of ceftazidime Pentahydrate and sulbactam sodium after subjected to Thermal degradation 
Am. J. Applied Sci., 6 (10): 1781-1787, 2009

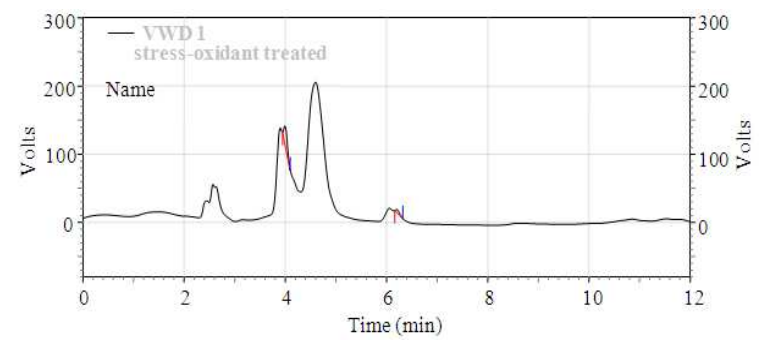

Fig. 4: Chromatogram of Ceftazidime Pentahydrate and sulbactam sodium after treating with oxidant

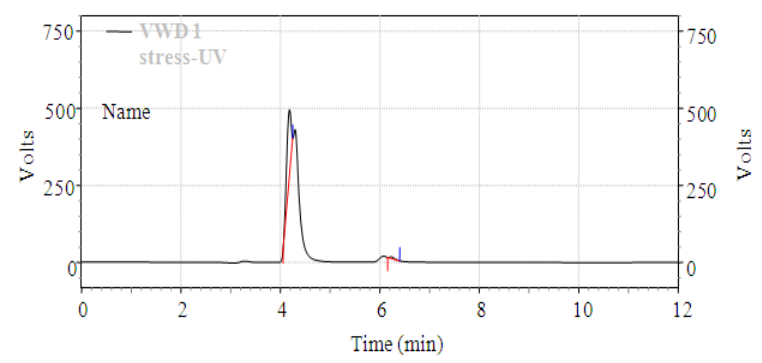

Fig. 5: Chromatogram of Ceftazidime Pentahydrate and sulbactam sodium after UV rays treatment

Peroxide degradation: Accurately weighed quanlity of Ceftazidime and Sulbactam equivalent to $50 \mathrm{mg}$ of ceftazidime and $25 \mathrm{mg}$ of sulbactam was transferred to $100 \mathrm{~mL}$ beaker to it $10 \mathrm{~mL}$ of $3 \% \mathrm{H}_{2} \mathrm{O}_{2}$ was added and kept in water bath at at $60^{\circ} \mathrm{C}$ for $4 \mathrm{~h}$. Cooled and sample was dissolved in $100 \mathrm{~mL}$ mobile phase. This solution was injected into the HPLC system. The chromatogram is shown in Fig. 4.

UV degradation: Accurately weighed quantity of Ceftazidime and Sulbactam equivalent to $50 \mathrm{mg}$ of ceftazidime and $25 \mathrm{mg}$ of sulbactam was transferred to100 $\mathrm{mL}$ beaker and was kept as such under UV light for $12 \mathrm{~h}$. Then sample was dissolved in $100 \mathrm{~mL}$ mobile phase. This solution was injected into the HPLC system. The chromatogram is shown in Fig. 5.

System suitability: System performance parameters of the developed HPLC method were determined by analyzing standard working solutions. Chromatographic parameters, such as number of theoretical plates $(\mathrm{N})$, resolution (Rs), capacity factor (k) and selectivity factor $(\alpha)$ were determined. The results are shown in (Table 1), indicating the good performance of the system. System repeatability was determined by five replicate injections of a working standard solution and the Relative Standard Deviations (RSD) of peak areas of both drugs were calculated to evaluate the repeatability. It was found that RSD for both the drugs was less than $2.0 \%$.
Table 1: System performance parameters for Ceftazidime and sulbactam sodium $(\mathrm{n}=5)$

\begin{tabular}{lllllll}
\hline Peak No. & Compounds & $\mathrm{t}_{\mathrm{R}}(\mathrm{min})$ & $\mathrm{N}$ & $\mathrm{K}$ & $\mathrm{R}_{\mathrm{S}}$ & $\alpha$ \\
\hline 1 & Sulbactam & 6.433 & 10509 & 246.948 & -- & -- \\
2 & Ceftazidime & 4.107 & 10350 & 246.730 & 1.72 & \\
& 0.64 & & & & & \\
\hline
\end{tabular}

Note: The chromatographic conditions used were: ODS Hypersil C18 Column, mobile phase of acetonitrile and $0.1 \mathrm{~N} \mathrm{TBAH} \mathrm{(25:75),}$ flow rate of $1.6 \mathrm{~mL} \mathrm{~min}{ }^{-1}$, detection wavelength of $230 \mathrm{~nm}$, room temperature $25^{\circ} \mathrm{C}, \mathrm{t}_{\mathrm{R}}$ : Retention time, $\mathrm{N}$ : Theoretical plates, $\mathrm{K}$ : Capacity factor, $\mathrm{R}_{\mathrm{S}}$ : Resolution, $\alpha$ : Selectivity factor

Linearity: Under the experimental conditions described above, linear calibration curves for both Ceftazidime pentahydrate and sulbactam sodium were obtained with five concentration level each. Peak Area (A) and Concentration (C) of each drug substance was subjected to regression analysis to calculate the regression equation and the correlation coefficients. The regression equation obtained were $\mathrm{A}=-0.325+0.0000081 \mathrm{C}(\mathrm{r}=0.9997$, $\mathrm{n}=5)$ for Ceftazidime and $\mathrm{A}=-0.3018+0.000154$ $\mathrm{C}(\mathrm{r}=0.9995, \mathrm{n}=5)$ for sulbactam sodium. The individual linearity range was $125-750 \mathrm{ppm}$ for ceftazidime and 62.5-375 ppm for sulbactam sodium. The results shows that within the tested concentration range there was excellent correlation between the peak area and the concentration of each drugs.

Limit of detection and limit of quantitation: Limit Of Detection (LOD) were established at a signal to noise ratio $(\mathrm{S} / \mathrm{N})$ of 3.3. Limit Of Quantification (LOQ) was established at a signal to noise ratio $(\mathrm{S} / \mathrm{N})$ of 10 . LOD and LOQ were experimentally verified by six injection of Ceftazidime and sulbactam sodium at the LOD and LOQ concentration. The LOD was calculated to be $0.11 \mathrm{ppm}$ and LOQ was found out to be $0.34 \mathrm{ppm}$.

Accuracy recovery: Accuracy was determined by applying the described method to synthetic mixtures of exipients to which known amount of each drug corresponding to 75,100 and $125 \%$ of label of claim had been added. The accuracy was then calculated as the percentage of analyte recovered by the assay. Mean recoveries (mean \pm SD) for Ceftazidime and sulbactam sodium from the combination formulation are shown in (Table 2) indicating good accuracy of the method for simultaneous determination of the two drugs.

Precision: System precision is the measure of the method variability that can be expected for a given analyst performing the analysis. Precision of the method was determined with the product. An amount of the product powder equivalent to 75,100 and $125 \%$ of label claim was weighed accurately and assayed in five replicate determinations for each of the three weighing amounts. The results for precision are shown in Table 2, 
Am. J. Applied Sci., 6 (10): 1781-1787, 2009

Table 2: Accuracy and precision of the HPLC method for simultaneous determination of Ceftazidime and sulbactam sodium

\begin{tabular}{llllll}
\hline & Accuracy & \multicolumn{5}{c}{ Precision (\%) } \\
Drugs & Mean & RSD & & \\
label claim & recovery \pm SD & $(\%, \mathrm{n}=9)$ & 75 & 100 & 125 \\
\hline Ceftazidime & $98.69 \pm 0.12$ & 0.12 & 0.19 & 0.11 & 0.39 \\
Sulbactam & $98.75 \pm 0.31$ & 0.31 & 1.17 & 0.74 & 0.37 \\
\hline
\end{tabular}

Note: The chromatographic conditions used were: ODS Hypersil C-18 Column, mobile phase of acetonitrile and 0.1 N TBAH (25:75), flow rate of

$1.6 \mathrm{~mL} \mathrm{~min}^{-1}$, detection wavelength of $230 \mathrm{~nm}$, room temperature $25^{\circ} \mathrm{C}$

Table 3: Assay results for Ceftazidime and sulbactam sodium sterile powder for injection (mean \pm SD)

\begin{tabular}{lcc}
\hline Batch No. & Sulbactam sodium & Ceftazidime \\
\hline 1 & $100.88 \pm 0.31$ & $100.54 \pm 0.53$ \\
2 & $99.81 \pm 0.23$ & $100.12 \pm 0.34$ \\
3 & $99.92 \pm 0.61$ & $100.30 \pm 0.12$ \\
\hline Note: The chromatographic conditions used were: ODS & Hypersil C-18 \\
Column, mobile phase of acetonitrile and $0.1 \mathrm{~N}$ TBAH (25:75), flow rate of \\
$1.6 \mathrm{~mL} \mathrm{~min}^{-1}$, detection wavelength of $230 \mathrm{~nm}$, room temperature $25^{\circ} \mathrm{C}$
\end{tabular}

indicating that acceptable precision was achieved for Ceftazidime and sulbactam sodium, as revealed by relative standard deviation data $(\mathrm{RSD}<2.0 \%$ in all of the levels of the two drugs.

Analytical solution stability: The stability of both the standard and the test was determined by monitoring the peak area of the standard solution and a sample solution of Ceftazidime and sulbactam sodium at 0, 6, 12 and 24 $\mathrm{h}$ at room temperature and refrigerated condition (2$\left.8^{\circ} \mathrm{C}\right)$. The results shows that there is no significant difference in the area for $24 \mathrm{~h}$.

Method application: The validated LC method was applied to the simultaneous determination of Zydotam for injection. The three batches of the sample were analyzed and the assay results, expressed as percentage of the label claim are shown in (Table 3). The result indicates that the amount of each drug in the injection corresponds to requirement.

Application of the proposed method in Spiked plasma: In a flcon tube Zydotam (containing Ceftazidime and Sulbactam inratio 2:1) was mixed with plasma to get a concentration of $1 \mathrm{mg} \mathrm{mL}{ }^{-1}$. The above plasma sample was then mixed with water and Acetonitrile (In ratio 1:2) to prepare a solution of $0.75 \mathrm{mg} \mathrm{mL}^{-1}$, then the plasma sample was incubated for $30 \mathrm{~min}$ at $4^{\circ} \mathrm{C}$ and was centrifuged for $15 \mathrm{~min}$ at $5000 \mathrm{rpm}$ and the superanent was collected and was analyzed as per the proposed method. The plasma sample was analyzed at 5 concentration level and recovery was found between $96.26-98.05 \%$ for Ceftazidime and $96.59-98.19 \%$ for Sulbactam. The chromatogram is shown in Fig. 6.

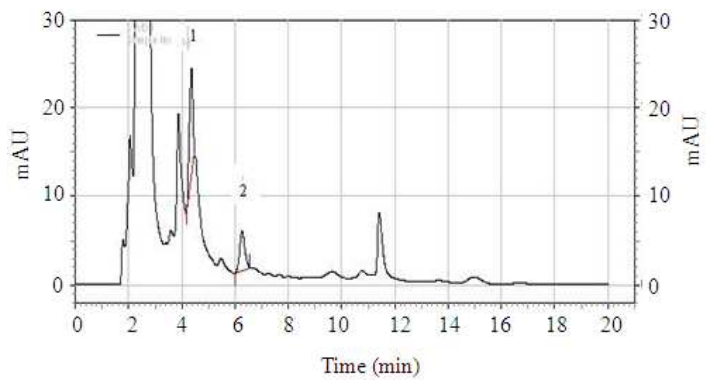

Fig. 6: A typical chromatogram of Ceftazidime (1) and Sulbactam (2) in spiked plasma sample

\section{CONCLUSION}

The developed Liquid chromatographic method with UV-Visible detection offers, sensitivity, precision and accuracy. It produces symmetric peak shape, good resolution and reasonable retention time for Ceftazidime and sulbactam sodium. Moreover there is no pretreatment of the sample which makes the method simple and easy to perform. It can be used for the simultaneous determination of Ceftazidime and sulbactam sodium in the pharmaceutical companies and research laboratories for routine analysis and in plasma samples.

\section{ACKNOWLEDGMENT}

The researchers are grateful to Chief General Manager, Domestic Operations, Venus Remedies Limited for providing samples of Zydotam.

\section{REFERENCES}

1. Fleming, P.C. and B. Knie, 1981. Activity of ceftazidime against Pseudomonas aeruginosa from bacteraemic and fibrocystic patients. J. Antimicrob. Chemother. $\quad 8:$ 169-173. http://jac.oxfordjournals.org/cgi/content/abstract/8/ suppl_B/169

2. Greenwood, D. and A. Eley, 1982. Comparative antipseudomonal activity of some newer betalactam agents. Antimicrob. Agents Chemother., 21: 204-209. http://aac.asm.org/cgi/content/abstract/21/2/204

3. Lees. L., J.A. Milson, A.K. Knirsch and K. Greenhakgh, 1986. Sulbactam plus ampicillin: Intrim review of efficacy and safety for therapeutic and prophylactic use. Rev. Infect. Dis., 8: S644-S65. http://www.jstor.org/stable/4454030 
4. United States Pharmacopoeia, 2004. National Formulary 22. Asian Edn., United States Pharmacopoeial Convention, Rockville, pp: 381, 1732-1733.

5. Rodenas, V., M.S. Garcia, C. Sanchez-Pedreno and M.I. Albero, 1997. Flow-injection spectrophotometric determination of frusemide or sulphathiazole in pharmaceuticals. J. Pharm. Biomed. Anal., 15: 1687-1693. DOI: 10.1016/S0731-7085(96)01963-2

6. K. Kelani, L. I. Bebaway and L. A. Fattah, J. "Stability-indicating spectrophotometric and densitometric methods for determination of some cephalosporins"AOAC. Int., 81,1998,386-396. http://cat.inist.fr/?aModele $=$ afficheN\&cpsidt $=2212479$

7. Moreno, A.D.H. and H.R.N. Salgado, 2008. Spectrophotometric determination of ceftazidime in pharmaceutical preparations using neocuproin as a complexing agent. Anal. Lett., 41: 2143-2152. http://www.informaworld.com/smpp/1356477

8. Marwa, S.E., S. Abdalla, M.N. Elbolkiny and M.H. Khalil, 2003. Spectrophotometric determination of aciclovir, ceftazidime pentahydrate, famotidine and isoxsuprine hydrochloride by ternary complex formation with eosin and $\mathrm{Cu}(\mathrm{II})$. Zhonghuá Yáoxué Zázhì, 55: 481-490. http://cat.inist.fr/?aModele=afficheN\&cpsidt=16105994

9. Hiremath, B. and B.H. Mruthyunjayaswamy, 2008. Development and validation of spectrophotometric methods for determination of ceftazidime in pharmaceutical dosage forms. Acta Pharm. 58: 275-85. http://www.ncbi.nlm.nih.gov/pubmed/19103564

10. Jiang, E. and $\mathrm{C}$. $\mathrm{Hu}, 2008$. Determination of ceftazidime and impurities using high performance liquid chromatography. $\mathrm{Se} \mathrm{Pu}, \quad 26$ : 75-79. http://www.ncbi.nlm.nih.gov/pubmed/18438029

11. Guitton, J., A. Laffont, J. Bruzeau, L.R. Mingret, J. Bonnefoy and M. Bureau, 1998. Determination of ceftazidime in plasma using high-performance liquid chromatography and electrochemical detection. Application for individualizing dosage regimens in elderly patients. J. Chromatogr. B. Biomed. Sci. Applied, 719: 151-157. http://www.ncbi.nlm.nih.gov/pubmed/9869375

12. Ayerton, J., 1981. Assay of ceftazidime in biological fluids using high-pressure liquid chromatography. J. Antimicrob. Chemother., 8: 227-231. http://jac.oxfordjournals.org/cgi/content/abstract/8/ suppl_B/227

13. Barnes, A.R., 1995. Determination of Ceftazidime and pyridine by HPLC: Application to a viscous eye drop formulation. J. Liquid Chromatogr., 18: 3117-3128. http://www.informaworld.com/smpp/content $\sim \mathrm{db}=\mathrm{a}$ ll $\sim$ content $=\mathrm{a} 756842555$
14. Ye, G., X. Cai, B. Wang, Z. Zhou, X. Yu, W. wang, J. Zhang, Y. Wang, J. Dong and Y. Jiang, 2009. Simultaneous determination of vancomycin and ceftazidime in cerebrospinal fluid in craniotomy patients by high-performance liquid chromatography. J. Pham. Biomed. Anal., 48: 860-865. DOI: 10.1016/J.JPBA.2008.06.012

15. Isla, A., A. Arzuaga, J. Maynar, A.R. Gascon, M.A. Solinis, E. Corral and J.L. Pedraz, 2005. Determination of ceftazidime and cefepime in plasma and dialysate-ultrafiltrate from patients undergoing continuous veno-venous hemodiafiltration by HPLC. J. Pharm. Biomed. Anal., 39: 996-1005. http://www.ncbi.nlm.nih.gov/pubmed/16026959

16. Haginaka, J., J. Wakai, H. Yasuda, T. Uno and T. Nakagawa, 1984. Spectrophotometric determination of sulbactam by reaction with 1,2,4triazole. Analyst, 109: 1057-1059. http://cat.inist.fr/?aModele $=$ afficheN\&cpsidt $=9043$ 550

17. Jelinek, I., H. Krejcirova, J. Dohan, Z. Roubal, V. Hola and V. Rejholec, 1990. Determination of sulbactam in human serum using capillary isotachophoresis. Cesk. Farm., 39: 305-307. http://www.ncbi.nlm.nih.gov/pubmed/2098203

18. Fredj, G., M. Paillet, F. Aussel, A. Brouard, H. Barreteau, C. Divine and M. Micaud, 1986. Determination of sulbactam in biological fluids by high-performance liquid chromatography. J. Chromatogr., 383: 218-222. http://cat.inist.fr/?aModele=afficheN\&cpsidt $=8216697$

19. Bowden, R.E. and P.O. Madsen, 1986. Highpressure liquid chromatographic assay of sulbactam in plasma, urine and tissue. Antimicrob. Agents Chemother., 30: 31-233. http://www.pubmedcentral.nih.gov/articlerender.fc gi? artid=180524

20. Haginaka, J., J. Wakai, H. Yasuda, T. Uno and T.N. Kagawa, 1985. High-performance liquid chromatographic assay of sulbactam using precolumn reaction with 1,2,4-triazole. J. Chromatogr., 341: 115-122. http://www.ncbi.nlm.nih.gov/pubmed/2991310

21. Haginaka, J., H. Yasuda, T. Uno and T. Nkagawa, 1984. Alkaline degradation and determination by high-performance by high-performance liquid chromatography. Chem. Pharm. Bull., 32: 2752-2758. http://cat.inist.fr/?aModele $=$ afficheN\&cpsidt $=9036$ 030

22. Foulds, G., D.J. Gans, D. Girard and T.J. Whall, 1986. Assays of sulbactam in the presence of ampicillin. Therm. Drug. Monit., 2: 223-237. http://www.ncbi.nlm.nih.gov/pubmed/3014686 
23. Shah, A.J., M.W. Adlard and J.D. Stride, 1990. A sensitive assay for clavulanic acid and sulbactam in biological fluids by high-performance liquid chromatography and precolumn derivatization. J. Pharm. Biomed. Anal., 5: 437-443. http://www.ncbi.nlm.nih.gov/pubmed/2081205

24. Fatma, A. Aly., N.A. Alarfaj and A.A. Alwarthan, 2000. Sensitive assay for clavulanic acid and sulbactam in pharmaceuticals and blood serum using a flow-injection chemiluminometric method. Anal. Chim. Acta, 414: 15-23. http://cat.inist.fr/?aModele $=$ afficheN\&cpsidt $=1362$ 949

25. Guillaume, Y., E. Peyrin and C. Guinchard, 1995. Rapid determination of sulbactam and tazobactam in human serum by high-performance liquid chromatography. J. Chromatorgr. B Biomed. Applied, 665: 363-371. http://www.ncbi.nlm.nih.gov/pubmed/7795816

26. Aparicio, I., M.A. Bello, M. Callejon and A. Guiraum, 2006. Simultaneous determination of rifampicin and sulbactam in mouse plasma by highperformance liquid chromatography. Biomed. Chromatogr., 8: 748-752. http://www.ncbi.nlm.nih.gov/pubmed/16252264
27. Mahgoub, H. and F.A. Aly, 1998. UVspectrophotometric determination of ampicillin sodium and sulbactam sodium in two-component mixtures. J. Pharm. Biomed. Anal., 8: 1273-1278. http://www.ncbi.nlm.nih.gov/pubmed/9800647

28. Wang, P., M. Qi, Y. Sun and J. Yang, 2004. A liquid chromatographic method for simultaneous determination of amoxicillin sodium and sulbactam sodium in a combination formulation. J. Pharm. Biomed. Anal., 36: 565-569. http://cat.inist.fr/?aModele=afficheN\&cpsidt=16411301

29. Qi, M.L., R.L. Chen, R.H. Cong and P. Wang, 2003. A validated method for simultaneous determination of piperacillin sodium and sulbactam sodium in sterile powder for injection by HPLC. J. Liquid Chrometrogr. Relat. Technol., 26: 665-676. http://cat.inist.fr/?aModele=afficheN\&cpsidt=14528577

30. Qi, M., P. Wang, Y. Sun and J. Wang, 2003. An LC method for simultaneous determination of amoxicillin and sulbactam pivoxil in a combination formulation. J. Liquid Chrometrogr. Relat. Technol., $\quad 26$ : 1927-1936. http://www.informaworld.com/smpp/content $\sim \mathrm{db}=\mathrm{a}$ 11 content=a713637867 